BMJ Open

Diabetes

Research

\& Care

\section{Exploring abnormal glucose metabolism in pregnancy among Australian Chinese migrants}

To cite: Li L-J, Zhang J, Shub A, et al. Exploring abnormal glucose metabolism in pregnancy among Australian Chinese migrants. BMJ Open Diab Res Care 2020;8:e000903. doi:10.1136/ bmjdrc-2019-000903

- Additional material is published online only. To view, please visit the journal online (http://dx.doi.org/10.1136/ bmjdrc-2019-000903).

Received 13 September 2019 Revised 26 December 2019 Accepted 4 January 2020
Check for updates

(c) Author(s) (or their employer(s)) 2020. Re-use permitted under CC BY-NC. No commercial re-use. See rights and permissions. Published by BMJ.

For numbered affiliations see end of article.

Correspondence to Dr Ling-Jun Li;

queenie.li.I.j@gmail.com

\section{ABSTRACT}

Objective Gestational diabetes mellitus (GDM) is a metabolic disorder of pregnancy that is increasingly prevalent among Chinese women. Few studies have examined whether the migration status of Chinese women contributes to the risks of developing GDM during pregnancy.

Research design and methods In this observational, cross-sectional and hospital-based study, we examined the prevalence of GDM and glycemic levels at oral glucose tolerance test (OGTT) among 491 Australian Chinese migrants $(n=491)$ and native Chinese $(n=1000)$. We defined GDM using the International Association of Diabetes and Pregnancy Study Groups guidelines. We collected data on maternal age, body mass index (BMI) and gestational age (GA) at booking and GA at delivery from medical records. We used multiple logistic and linear regression models to calculate the $\mathrm{OR}$ of having GDM and mean differences in glycemic levels in Australian Chinese migrants, relative to native Chinese.

Results Age-at-booking and BMI-at-booking adjusted GDM prevalence was significantly higher in Australian Chinese migrants than native Chinese $(19.7 \%$ vs $14.6 \%$; $\mathrm{p}=0.01$ ). After adjusting for age, $\mathrm{BMI}$ at booking and $\mathrm{GA}$ at booking, fasting glucose levels were significantly lower ( $\beta-0.08 \mathrm{mmol} / \mathrm{L} ; 95 \% \mathrm{Cl}-0.14$ to 0.02 ), while 2-hour glucose levels were significantly higher $(0.22 \mathrm{mmol} / \mathrm{L}$; 0.02 to 0.43 ) in Australian Chinese immigrants than native Chinese.

Conclusions Migration status may be a marker for abnormal glucose metabolism during pregnancy among Australian Chinese migrants, possibly due to socioeconomic disadvantages and lifestyle changes associated with migration.

\section{INTRODUCTION}

Gestational diabetes mellitus (GDM) is defined as hyperglycemia first detected in pregnancy that is less than overt diabetes. ${ }^{1}$ GDM is associated with adverse maternal and offspring events, including hypertensive disorders in pregnancy, cesarean delivery, postpartum maternal type 2 diabetes (T2D), offspring macrosomia and childhood obesity. ${ }^{2}$ Compared with women of European descent, Chinese women are at higher risk of developing GDM. ${ }^{13-5}$ Identifying women at risk of GDM, especially in the

\section{Significance of this study}

What is already known about this subject?

- Chinese immigrants have become a large and important part of Western populations.

- The process of assimilating into Western lifestyles has increased the risk of developing adverse cardiac-metabolic health, yet little is known of the risk of developing gestational diabetes mellitus (GDM).

What are the new findings?

- Compared with native Chinese during pregnancy, Australian Chinese immigrants had:

higher GDM prevalence;

higher postchallenge glucose levels;

lower fasting glucose levels.

- Our results suggest that migration status may be a marker for abnormal glucose metabolism during pregnancy among Australian Chinese migrants, possibly due to socioeconomic disadvantages and lifestyle changes associated with migration.

How might these results change the focus of research or clinical practice?

- Efforts to improve dietary habits and lifestyle practices of Chinese female migrants might be effective in reducing the risk of developing GDM and other cardiovascular health conditions among Chinese migrants residing in the Western world.

Chinese population, may inform intervention strategies to reduce the rates of GDM.

In addition to traditional risk factors for GDM such as lower socioeconomic status, excessive weight gain and sedentary lifestyle during pregnancy, maternal overweight or obesity, family history of diabetes and history of GDM or macrosomia, ${ }^{1}{ }^{4}$ emerging evidence has suggested migration to be a potential risk factor for GDM. One study suggested South Asian mothers (ie, Bangladeshis, Sri Lankans, Indians and Pakistanis), who were of lower socioeconomic status (ie, lower maternal education level and health insurance coverage), had higher risks of GDM relative to US-born non-Hispanic whites, all 
of whom resided in New Jersey. ${ }^{6}$ Another study reported that in New Zealand, Asian-born women had threefold to fourfold higher risk of GDM compared with women born in New Zealand. ${ }^{7}$ However, there are no data on the differential prevalence of GDM among Chinese migrants residing in high-income countries.

In the past century, Chinese migrants have become a large part of Western populations. ${ }^{8-12}$ For example, in Australia, Chinese people represented $8.3 \%$ of the overseas-born population in 2016 and are the most common source of Asian migrants. ${ }^{10}$ Typically, migrants undergo a gradual and continuous process of assimilating into local lifestyles and behaviors (ie, dietary habits, social relations, level of stress, children's preferences) of the country or region of residence. ${ }^{13} 14$ This shift in dietary habits (ie, increased consumption of fats / sweets, dairy products, convenience food and a reduction in fruits and vegetables) ${ }^{15}$ is believed to lead to adverse health outcomes. ${ }^{915-19}$ Asian migrants living in Europe and North America have a greater body mass index $(\mathrm{BMI})^{20}$ and higher rates of chronic disease including hypertension, T2D, metabolic syndrome, psychological condition or psychiatric disease, cardiovascular disease and even cancer. ${ }^{19}{ }^{21-23}$ Females are also more likely to be negatively affected by adverse behavioral changes that stem from migration exposure (ie, increased intake of convenience food, less social support and increased stress and loneliness, unavailability of traditional foods and ingredients, substitution of comfort food in high fat/ sugar). ${ }^{18}{ }^{24}$ Investigating the prevalence of GDM among Chinese female migrants may inform health promotion and prevention strategies. ${ }^{25}$

To address these gaps, we examined and compared the prevalence of GDM and gestational glucose levels between Australian Chinese migrants $(n=491)$ and native Chinese $(n=1000)$, from two representative tertiary metropolitan hospitals in Australia (Melbourne) and China (Shanghai). ${ }^{26}$ We hypothesized that Australian Chinese migrants would be at higher risk of GDM and have higher glucose levels during pregnancy than native Chinese.

\section{METHODS}

\section{Study population and design}

The current investigation is a substudy of the Integrated Platform for Research in Advancing Metabolic Health Outcomes of Women and Children-International (IPRAMHO-International) Collaborative Study. This study is built on the IPRAMHO Asia-Pacific study group, which provides a platform for clinicians from countries in the Asia-Pacific region to share their experience or clinical practices of screening, diagnosing and treating GDM during pregnancy and after delivery. ${ }^{26} 27$ We obtained delivery electronic records from a total of 6851 singleton pregnancies born in one calendar year in Australia and 1000 singleton pregnancies in China. ${ }^{26}$ We restricted our analyses to 491 pregnant subjects from
Australia who were of Chinese ethnicity and born outside of Australia (including China Mainland, Taiwan and Hong Kong Special Administrative Region (SAR)). We applied simple random sampling method ${ }^{28} 29$ to select 1000 pregnant subjects from a Chinese cohort (Shanghai birth cohort, $\mathrm{n}=3692)^{30}$ (online supplementary figure 1 ).

\section{Exposure, outcomes and co-variates measures}

We defined Chinese subjects' migration status and analyzed it as the exposure in this study. According to their country of birth and permanent residence, we categorized migration status as: (1) Australian Chinese migrants who were born in China Mainland, Taiwan or Hong Kong SAR, but subsequently immigrated to and permanently resided in Australia $(n=491)$; (2) Native Chinese as those who were born and permanently resided in China Mainland $(\mathrm{n}=1000)$.

At 24-28 weeks of gestation, trained staff in both hospitals performed $75 \mathrm{~g}$ oral glucose tolerance test (OGTT) and measured fasting, 1-hour and 2-hour glucose levels. Clinicians from both sites diagnosed GDM using the International Association of Diabetes and Pregnancy Study Groups guidelines ${ }^{31}$ (fasting glucose $\geq 5.1 \mathrm{mmol} / \mathrm{L}$; and/or 1-hour glucose level $\geq 10.0 \mathrm{mmol} / \mathrm{L}$; and/or 2-hour glucose level $\geq 8.5 \mathrm{mmol} / \mathrm{L}$ ). We further categorized GDM into three additional phenotypes based on individual OGTT readings: (1) fasting glucose impairment alone (fasting glucose $\geq 5.1 \mathrm{mmol} / \mathrm{L}$ and 1-hour glucose level $<10.0 \mathrm{mmol} / \mathrm{L}$ and 2-hour glucose level $<8.5 \mathrm{mmol} / \mathrm{L}$ ); (2) postchallenge glucose intolerance alone (either 1-hour glucose level $\geq 10.0 \mathrm{mmol} / \mathrm{L}$ or 2-hour glucose level $\geq 8.5 \mathrm{mmol} / \mathrm{L}$ and fasting glucose $<5.1 \mathrm{mmol} / \mathrm{L}$ ); (3) both fasting and postchallenge glucose abnormality (either 1-hour glucose level $\geq 10.0 \mathrm{mmol} / \mathrm{L}$ or 2-hour glucose level $\geq 8.5 \mathrm{mmol} / \mathrm{L}$ and fasting glucose $\geq 5.1 \mathrm{mmol} / \mathrm{L}$ ). We analyzed GDM diagnosis, phenotypes and individual OGTT readings as outcomes.

In both hospitals, we obtained data on maternal age, height, weight at first booking ( $\leq 13$ weeks of gestation), gestational age (GA) at first booking and GA at delivery from medical records. Mercy Hospital for Women additionally collected information on offspring sex and birth weight. We calculated BMI at booking as weight at booking in kilograms divided by the square of height in meters. ${ }^{32}$

\section{Statistical analysis}

We examined distributions on all continuous variables. We compared all maternal characteristics between Australian Chinese immigrants and native Chinese using Student's t-test or Mann-Whitney U test for continuous variables (based on normality of distribution) and $\chi^{2}$ test for categorical variables.

We calculated crude, as well as age-adjusted and BMIadjusted prevalence of GDM in both hospitals. We used multiple logistic regression models to calculate the OR of having GDM or glycemic-defined GDM phenotypes, and generalized linear regression models (GLM) to calculate 
Table 1 Demographics between Australian Chinese migrants and native Chinese

\begin{tabular}{|c|c|c|c|}
\hline Demographics & $\begin{array}{l}\text { Australian Chinese } \\
\text { immigrants* } n=491\end{array}$ & $\begin{array}{l}\text { Native Chinese } \\
n=1000\end{array}$ & $\mathbf{P}$ value† \\
\hline Maternal age, years & $32.7(4.4)$ & $29.1(3.9)$ & $<0.001$ \\
\hline BMl at booking, $\mathrm{kg} / \mathrm{m}^{2}$ & $22.4(3.5)$ & $22.2(3.0)$ & 0.20 \\
\hline GA at booking, weeks & $15.7(7.4)$ & $15.0(2.0)$ & 0.01 \\
\hline Nulliparous, yes (\%) & $225(45.8 \%)$ & $1000(100 \%)$ & $<0.001$ \\
\hline \multicolumn{4}{|l|}{ GDM point prevalence } \\
\hline Crude, n (\%) & $97(19.8 \%)$ & $146(14.6 \%)$ & 0.01 \\
\hline Adjusted for age and BMI at booking, $\mathrm{n}(\%)$ & $97(19.7 \%)$ & $146(14.6 \%)$ & 0.01 \\
\hline Fasting glucose, $\mathrm{mmol} / \mathrm{L}$ & $4.4(0.7)$ & $4.5(0.4)$ & 0.02 \\
\hline 1-hour glucose level, $\mathrm{mmol} / \mathrm{L}$ & $7.8(2.2)$ & $7.6(1.6)$ & 0.02 \\
\hline 2-hour glucose level, $\mathrm{mmol} / \mathrm{L}$ & $6.8(1.9)$ & $6.4(1.3)$ & $<0.001$ \\
\hline GA at delivery, weeks & $38.9(1.8)$ & $39.4(1.5)$ & $<0.001$ \\
\hline Male offspring, yes (\%) & $264(53.8 \%)$ & -- & -- \\
\hline Offspring birth weight, g & $3278.4(508.3)$ & -- & -- \\
\hline
\end{tabular}

$P$ value $<0.05$ is italized.

${ }^{*}$ Born in either China Mainland, Taiwan or Hong Kong.

†Student's t-test and $\chi^{2}$ test between Australian Chinese immigrants and native Chinese residents.

BMI, body mass index; GA, gestational age; GDM, gestational diabetes mellitus.

mean difference in OGTT levels in Australian Chinese immigrants relative to native Chinese subjects, respectively. We applied the following models: model 1, unadjusted; model 2, adjusted for age, BMI at booking and GA at booking. We conducted all analyses using STATA (V.14.0, StataCorp, Texas, USA).

\section{RESULTS}

Table 1 shows the demographic characteristics of the study participants. Australian Chinese migrants tended to be older ( 32.7 vs 29.1 years, $p<0.001$ ), had earlier GA at delivery (38.9 vs 39.4 weeks, $\mathrm{p}<0.001$ ) and yet similar BMI at booking (22.4 vs $22.2 \mathrm{~kg} / \mathrm{m}^{2}, \mathrm{p}=0.20$ ) compared with native Chinese. Due to the one-child policy in China, all native Chinese were nulliparous while $45.8 \%$ of the Australian Chinese migrants were nulliparous. The crude $(19.8 \%$ vs $14.6 \%, \mathrm{p}=0.01)$ as well as age-atbooking and BMI-at-booking adjusted GDM prevalence $(19.7 \%$ vs $14.6 \% ; \mathrm{p}=0.01)$ was significantly higher in Australian Chinese migrants than in native Chinese. Similarly, Australian Chinese migrants had lower fasting glucose levels ( 4.4 vs $4.5 \mathrm{mmol} / \mathrm{L}, \mathrm{p}=0.02$ ) and yet higher postchallenge glucose levels ( 1 hour: 7.8 vs $7.6 \mathrm{mmol} / \mathrm{L}$, $\mathrm{p}=0.02$; 2 hours: 6.8 vs $6.4 \mathrm{mmol} / \mathrm{L}, \mathrm{p}<0.001)$, compared with native Chinese. In addition, Australian Chinese immigrants had slightly more than half of the offspring as boys, and the average weight of infants was $3278.4 \mathrm{~g}$ (SD 508.3) at delivery.

The majority of the GDM cases in both Australian Chinese migrants (67 out of 97, 69.1\%) and native Chinese ( 88 out of $146,60.3 \%$ ) were the result of postchallenge glucose intolerance alone. A lower proportion of GDM due to fasting glucose impairment alone was observed in
Australian Chinese immigrants than in native Chinese subjects $(8.2 \%$ vs $24.7 \% ; \mathrm{p}=0.01)$. A higher proportion of GDM due to both fasting and postchallenge glucose abnormality was observed in Australian Chinese immigrants than in native Chinese $(15.5 \%$ vs $10.3 \%, \mathrm{p}=0.044)$ (figure 1). Excluding mothers without OGTT readings, the overall distribution of three GDM phenotypes in two hospital showed significant difference $(\mathrm{p}=0.005)$.

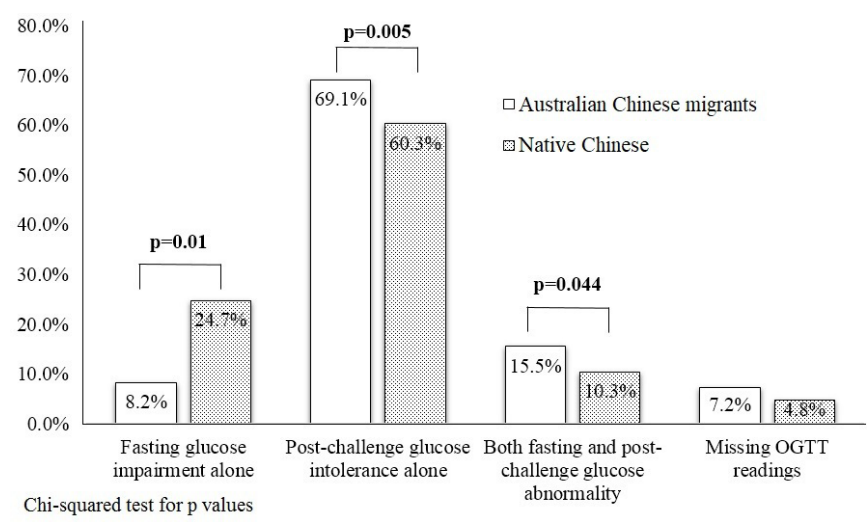

Figure 1 The comparison of each gestational diabetes mellitus (GDM) phenotype proportion between Australian Chinese migrants and native Chinese. White column represents Australian China migrants while black dotted column represents native Chinese. Four groups are displayed as 'fasting glucose impairment alone, postchallenge glucose intolerance alone, both fasting and postchallenge glucose abnormality and missing OGTT readings'. comparisons with ratio and $p$ value between Australian Chinese migrants and native Chinese are shown in each GDM phenotypes except for the missing OGTT readings group. OGTT, oral glucose tolerance test. 
Table 2 GDM prevalence between Australian Chinese migrants and native Chinese

\begin{tabular}{|c|c|c|}
\hline $\begin{array}{l}\text { GDM prevalence } \\
\text { and GDM } \\
\text { phenotypes } \\
\text { prevalence }\end{array}$ & $\begin{array}{l}\text { Australian Chinese } \\
\text { immigrants } \\
(\mathrm{OR}, 95 \% \mathrm{Cl}) \mathrm{P} \text { value }\end{array}$ & $\begin{array}{l}\text { Native } \\
\text { Chinese }\end{array}$ \\
\hline \multicolumn{3}{|l|}{ GDM onset } \\
\hline Model 1 & $\begin{array}{l}1.44(1.09 \text { to } 1.91) \\
p=0.01\end{array}$ & Reference \\
\hline Model 2 & $\begin{array}{l}1.15(0.82 \text { to } 1.61) \\
p=0.41\end{array}$ & Reference \\
\hline \multicolumn{3}{|c|}{ Fasting glucose impairment alone } \\
\hline Model 1 & $\begin{array}{l}0.38(0.18 \text { to } 0.81) \\
p=0.01\end{array}$ & Reference \\
\hline Model 2 & $\begin{array}{l}0.30(0.12 \text { to } 0.76) \\
p=0.01\end{array}$ & Reference \\
\hline \multicolumn{3}{|c|}{ Postchallenge glucose intolerance alone } \\
\hline Model 1 & $\begin{array}{l}1.61(1.15 \text { to } 2.24) \\
p<0.01\end{array}$ & Reference \\
\hline Model 2 & $\begin{array}{l}1.26(0.85 \text { to } 1.85) \\
p=0.25\end{array}$ & Reference \\
\hline \multicolumn{3}{|c|}{ Both fasting and postchallenge glucose abnormality } \\
\hline Model 1 & $\begin{array}{l}2.07(1.00 \text { to } 4.27) \\
p=0.05\end{array}$ & Reference \\
\hline Model 2 & $\begin{array}{l}1.86(0.81 \text { to } 4.26) \\
p=0.14\end{array}$ & Reference \\
\hline
\end{tabular}

$P$ value $<0.05$ is italized

Model 1, unadjusted.

Model 2, adjusted for age, BMI at first booking and GA at booking. $\mathrm{BMI}$, body mass index; GA, gestational age; GDM, gestational diabetes mellitus.

In multiple logistic regression analyses, Australian Chinese immigrants had higher odds (OR 1.44, 95\% CI 1.09 to 1.91) of GDM complicated pregnancies compared with native Chinese (table 2). In addition, compared with native Chinese, Australian Chinese immigrants had higher odds of GDM due to postchallenge glucose intolerance alone $(1.61 ; 1.15$ to 2.24$)$ or both fasting and postchallenge glucose abnormality (2.07; 1.00 to 4.27$)$, but lower odds of having GDM due to fasting glucose impairment alone $(0.38 ; 0.18$ to 0.81$)$. After adjusting for maternal age and BMI-at-booking and GA at booking, most of the reported estimates attenuated to null, except for associations with GDM due to fasting glucose impairment alone $(0.30 ; 0.12$ to 0.76$)$.

In unadjusted linear regression analysis, Australian Chinese migrants tended to have lower fasting glucose levels (mean difference: $-0.07 \mathrm{mmol} / \mathrm{L} ; 95 \% \mathrm{CI}-0.13$ to -0.01 ) and higher postchallenge glucose levels (1 hour: $0.26 \mathrm{mmol} / \mathrm{L} ; 0.04$ to 0.49 ; 2 hours: $0.35 \mathrm{mmol} / \mathrm{L} ; 0.17$ to 0.54) than native Chinese (table 3). After adjusting for confounders, fasting glucose levels remained consistently lower $(-0.08 \mathrm{mmol} / \mathrm{L} ;-0.14$ to -0.02$)$, while 2-hour glucose levels remained higher $(0.22 \mathrm{mmol} / \mathrm{L} ; 0.02$ to
Table 3 Comparison of OGTT glucose readings between Australian Chinese migrants and native Chinese

\begin{tabular}{|c|c|c|}
\hline $\begin{array}{l}75 \mathrm{~g} \text { OGTT } \\
\text { readings }\end{array}$ & $\begin{array}{l}\text { Australian Chinese migrants } \\
\text { (mean difference, } 95 \% \mathrm{Cl} \text { ) }\end{array}$ & $\begin{array}{l}\text { Native } \\
\text { Chinese }\end{array}$ \\
\hline \multicolumn{3}{|c|}{ Fasting glucose level, $\mathrm{mmol} / \mathrm{L}$} \\
\hline Model 1 & $-0.07(-0.13$ to -0.01$) p=0.02$ & Reference \\
\hline Model 2 & $-0.08(-0.14$ to -0.02$) p=0.02$ & Reference \\
\hline \multicolumn{3}{|c|}{ 1-hour glucose level, $\mathrm{mmol} / \mathrm{L}$} \\
\hline Model 1 & 0.26 (0.04 to 0.49$) p=0.02$ & Reference \\
\hline Model 2 & $0.09(-0.15$ to 0.33$) p=0.45$ & Reference \\
\hline \multicolumn{3}{|c|}{ 2-hour glucose level, $\mathrm{mmol} / \mathrm{L}$} \\
\hline Model 1 & 0.35 (0.17 to 0.54$) p<0.001$ & Reference \\
\hline Model 2 & 0.22 (0.02 to 0.43$) p=0.03$ & Reference \\
\hline
\end{tabular}

$P$ value $<0.05$ is italized

Model 1, unadjusted.

Model 2, adjusted for age, BMI at first booking and GA at booking.

BMI, body mass index; GA, gestational age.

0.43) in the Australian Chinese migrants than their counterparts in China.

\section{DISCUSSION}

Our study from two tertiary hospitals in Australia and China showed that GDM prevalence was higher in Australian Chinese migrants than native Chinese. A substantial majority of GDM cases in both groups were due to postchallenge glucose intolerance alone. Furthermore, Australian Chinese migrants tended to have lower fasting glucose levels, yet higher postchallenge glucose levels than native Chinese. Our results suggest that migration may be a potential marker for abnormal glucose metabolism during pregnancy among Chinese women residing in Australia.

The past few decades have shown a growth in research focusing on Chinese migrants' health and acculturation in Western world, driven by the increasing number of Chinese migrants globally. ${ }^{80-12}$ Studies in Australia and other Western countries have shown that trends in lifestyle changed among Asians after migration, including increased consumption of take-away foods, decreased intake of fruits and vegetables, elevated degree of social strain and higher intake of red meats and dairy products. $^{16} 171933$ 34 For example, in a review on Chinese migrants in Australia, researchers found substantial alteration or substitution of food items in their diet such as increased usage of fatty meat or cooking oil and soda consumption, instead of green leafy vegetable cooking and Chinese tea drinking. ${ }^{17}$ Breakfast cereal, bread and potato slowly replaced rice as the main food staple in all meals. ${ }^{17}$ In addition, potato has become the substitute for sweet potato and yam, and cheese slowly took the place of tofu or bean curd in routine meals. ${ }^{17}$

As widely reported, sweetened beverages, high fat and protein diet, low fiber diet and lack of physical activity 
have shown associations with excess adiposity and adverse health outcomes, ${ }^{3536}$ since it elevates inflammation in vivo, ${ }^{37-39}$ and also induces insulin resistance. ${ }^{40}{ }^{41}$ In addition, other contextual factors related to migration such as failure to integrate into the new society, feelings of loneliness and exclusion, unemployment and unhealthy lifestyles ${ }^{18} 4243$ might worsen the cycle of unhealthy food intake and poor health outcomes. Recent studies have also shown that adverse psychosocial risks such as depression and anxiety could contribute to oxidative stress, ${ }^{44} 45$ endothelial dysfunction, ${ }^{45}$ inflammation ${ }^{45}$ and insulin resistance, ${ }^{46}$ eventually contributing towards the development of cardiometabolic disease. Migrants from non-English-speaking backgrounds (ie, Mediterranean, South Asian, South-East Asian, African or South Pacific Island) are more likely to develop diabetes or coronary heart disease. ${ }^{1722} 2334$ Unhealthy dietary habits coupled with reduced physical activity and a degree of isolation in social circles have greater negative consequences for female migrants, who are doubly marginalized as being a woman and a foreigner. ${ }^{16} 1824$ These findings may explain our observations of a higher prevalence of GDM among the Australian Chinese migrants than the native Chinese, even after adjusting for age, BMI at booking and GA at booking.

We did not observe differences in BMI at booking, yet found differences in glucose levels between Australian Chinese migrants and native Chinese. Even though adiposity is a major contributor for insulin resistance, the pathogenesis of GDM is multifactorial, including insulin secretion insufficiency and insulin resistance. ${ }^{47}$ We observed that Australian Chinese migrants had lower odds of fasting glucose impairment, yet had higher odds of postchallenge glucose intolerance than native Chinese. As we know, GDM is likely a heterogeneous condition $^{48}$ and thus, its underlying pathophysiological mechanism varies. Past studies have established that obesity or excessive adiposity could drive the increment in liver fat, hepatic glucose overproduction, reduced insulin action and inadequate beta cell expansion and function, ${ }^{49}{ }^{50}$ all of which might lead to elevated fasting glucose in vivo. On the contrary, increased production of inflammatory cytokines (ie, interleukin-6, tumor necrosis factor- $\alpha)^{47} 51$ and placental hormones (ie, placental lactogen ${ }^{4752}$ could affect the muscles (through reduction in both glucose uptake and insulin receptor substrate 1 protein secretion ${ }^{47}$ and pancreas (through increased beta cell mass and dysfunction). ${ }^{47}$ Such phenomena may not necessarily be related to adiposity and could affect postchallenge glucose tolerance and ultimately, elevate postchallenge glucose levels.

The public health importance of our findings is notable. Since the Chinese migrant population is large and growing in Australia, studies that examine the underlying pathophysiology of GDM and subsequent conversion to T2D in female migrants living in high-income countries are needed. This merits further attention from health professionals caring for Chinese migrants, given the known consequences of GDM on both mothers and their offspring. ${ }^{2}$ Moreover, women have the strongest influence on nutrition and health behaviors of all members in the family. ${ }^{18}$ Efforts to improve dietary habits and lifestyle practices of Chinese female migrants might be effective in reducing the risk of developing pregnancy complications like GDM among these women.

The strength of our study is a relatively large and representative sample of Chinese pregnant women including immigrants in Australia and natives in China Mainland. All medical examinations were done in tertiary hospitals according to standardized protocols. However, there are noteworthy limitations in our study. First, our findings may be biased by residual confounding from data that were unavailable in our study, such as length of residence in Australia, urban or rural residency, physical activity record, household income, maternal education and other sociodemographic characteristics, psychosocial evaluation, GA at GDM diagnosis and fetal sex. In addition, all pregnancies were nulliparous among Shanghai study subjects and thus, parity cannot be considered as a major confounder in our analyses. Second, even though the Han ethnic group is known to be the majority in Chinese societies including China Mainland, Taiwan, Hong Kong SAR and overseas, systematic differences in lifestyles, beliefs and dietary habits and even Chinese ethnicity (ie, Han) among these regions ${ }^{53}$ may have also biased our study findings.

\section{CONCLUSION}

Our study showed that Australian Chinese migrants were more likely to have GDM, predominantly from postchallenge glucose intolerance alone than fasting glucose impairment alone, than native Chinese subjects. Migration may be a potential marker for abnormal glucose metabolism during pregnancy among Chinese females residing in Australia, possibly due to suboptimal lifestyles (ie, overnutrition and sedentary activity) and socioeconomic disadvantage. Further research using a larger population sample and comprehensive variables (ie, socioeconomic characteristics and length of migration, and birth outcomes) is warranted to explore this relationship in migrants' health.

\section{Author affiliations}

${ }^{1}$ Department of Obstetrics and Gynaecology, KK Women's and Children's Hospital, Singapore

${ }^{2}$ Department of Obstetrics and Gynaecology, Yong Loo Lin School of Medicine, National University of Singapore, Singapore

${ }^{3}$ Ministry of Education and Shanghai Key Laboratory of Children's Environmental Health, Xinhua Hospital, Shanghai Jiaotong University School of Medicine,

Shanghai, China

${ }^{4}$ Perinatal Department, Mercy Women Hospital, Melbourne, Victoria, Australia ${ }^{5}$ Department of Population Medicine, Harvard Pilgrim Health Care Institute, Harvard Medical School, Boston, Massachusetts, USA

Contributors L-JL designed the study, performed data analyses, interpreted the results and wrote the whole manuscript. JZ and AS provided the data and edited the manuscript. IA reviewed and edited the manuscript. KHT designed the study, 
reviewed and edited the manuscript. L-JL is responsible for the integrity of the work as a whole.

Funding This work was supported by Singapore National Medical Research Council (NMRC) KKH Centre Grant (NMRC/CG/C008A/2017_KKH) and NMRC Transition Award (NMRC TA/0027/2014).

Competing interests None declared.

Patient consent for publication Not required.

Ethics approval The SingHealth Centralised Institutional Review Board and National Health Group's Domain Specific Review Board approved the study, while Mercy Health Human Research Committee (2018-016) and Ethics Committee of Xinhua Hospital Affiliated to Shanghai Jiaotong University School of Medicine (XHECC-2013-001-2) approved the data collection from both study sites.

Provenance and peer review Not commissioned; externally peer reviewed.

Data availability statement Data are available upon request.

Open access This is an open access article distributed in accordance with the Creative Commons Attribution Non Commercial (CC BY-NC 4.0) license, which permits others to distribute, remix, adapt, build upon this work non-commercially, and license their derivative works on different terms, provided the original work is properly cited, appropriate credit is given, any changes made indicated, and the use is non-commercial. See: http://creativecommons.org/licenses/by-nc/4.0/.

ORCID iD

Ling-Jun Li http://orcid.org/0000-0003-0685-3189

\section{REFERENCES}

1 Mclntyre HD, Catalano P, Zhang C, et al. Gestational diabetes mellitus. Nat Rev Dis Primers 2019;5:47.

2 Buchanan TA, Xiang AH, Page KA. Gestational diabetes mellitus: risks and management during and after pregnancy. Nat Rev Endocrinol 2012;8:639-49.

3 Chong Y-S, Cai S, Lin H, et al. Ethnic differences translate to inadequacy of high-risk screening for gestational diabetes mellitus in an Asian population: a cohort study. BMC Pregnancy Childbirth 2014:14:345

4 Gilmartin ABH, Ural SH, Repke JT, et al. Gestational diabetes mellitus. Rev Obstet Gynecol 2008;1:129-34.

5 Hedderson M, Ehrlich S, Sridhar S, et al. Racial/Ethnic disparities in the prevalence of gestational diabetes mellitus by BMI. Diabetes Care 2012;35:1492-8.

6 Sanchalika A, Teresa J. Risk of gestational diabetes among south asian immigrants living in New Jersey--a retrospective data review. $J$ Racial Ethn Health Disparities 2015;2:510-6.

7 McDonald R, Karahalios A, Le T, et al. A retrospective analysis of the relationship between ethnicity, body mass index, and the diagnosis of gestational diabetes in women attending an Australian antenatal clinic. Int J Endocrinol 2015;2015:297420

8 Report on the demographic situation in Canada. permanent and temporary immigration to Canada from 2012 to 2014, 2014. Available: https://www150statcangcca/n1/pub/91-209-x/2016001/ article/14615-enghtm

9 Rosenmöller DL, Gasevic D, Seidell J, et al. Determinants of changes in dietary patterns among Chinese immigrants: a cross-sectional analysis. Int J Behav Nutr Phys Act 2011;8:42.

10 Population and migration statistics in Australia, 2018. Available: https://wwwaphgovau/About_Parliament/Parliamentary Departments/Parliamentary_Library/pubs/BriefingBook45p/ MigrationFlows

11 People in the EU: who are we and how do we live?2015. Available: https://eceuropaeu/eurostat/documents/3217494/7089681/KS-0415-567-EN-Npdf

12 The foreign born from Asia: 2011, 2012. Available: https:// www2censusgov/library/publications/2012/acs/acsbr11-06pdf

13 Yusuf S, Reddy S, Ounpuu S, et al. Global burden of cardiovascular diseases: Part II: variations in cardiovascular disease by specific ethnic groups and geographic regions and prevention strategies. Circulation 2001:104:2855-64.

14 Constant AF, García-Muñoz T, Neuman S, et al. A "healthy immigrant effect" or a "sick immigrant effect"? Selection and policies matter. Eur J Health Econ 2018;19:103-21.

15 Pan YL, Dixon Z, Himburg S, et al. Asian students change their eating patterns after living in the United States. J Am Diet Assoc 1999:99:54-7.

16 Zhang $\mathrm{H}$, Hsu-Hage $\mathrm{BH}-\mathrm{H}$, Wahlqvist ML. Longitudinal changes in nutrient intakes in the Melbourne Chinese cohort study. Public Health Nutr 2002;5:433-9.
17 Wahlqvist ML. Asian migration to Australia: food and health consequences. Asia Pac J Clin Nutr 2002;11:S562-8.

18 Popovic-Lipovac A, Strasser B. A review on changes in food habits among immigrant women and implications for health. J Immigrant Minority Health 2015;17:582-90.

19 Holmboe-Ottesen G, Wandel M. Changes in dietary habits after migration and consequences for health: a focus on South Asians in Europe. Food Nutr Res 2012;56:18891.

20 Lee MM, Wu-Williams A, Whittemore AS, et al. Comparison of dietary habits, physical activity and body size among Chinese in North America and China. Int J Epidemiol 1994;23:984-90.

21 Gong Z, Zhao D. Cardiovascular diseases and risk factors among Chinese immigrants. Intern Emerg Med 2016;11:307-18.

22 Hyman I, Guruge S, Makarchuk M-J, et al. Promotion of healthy eating among new immigrant women in Ontario. Can J Diet Pract Res 2002;63:125-9.

23 Dekker LH, Snijder MB, Beukers MH, et al. A prospective cohort study of dietary patterns of non-Western migrants in the Netherlands in relation to risk factors for cardiovascular diseases: HELIUSDietary patterns. BMC Public Health 2011;11:441.

24 Carballo M, Grocutt M, Hadzihasanovic A. Women and migration: a public health issue. World Health Stat Q 1996;49:158-64.

25 Williams $\mathrm{E}$, Harris $\mathrm{N}$. Understanding the nutrition information needs of migrant communities: the needs of African and Pacific Islander communities of Logan, Queensland. Public Health Nutr 2011;14:989-94.

26 Li L-J, Yu Q, Tan KH, et al. Clinical practice of diabetic pregnancy screening in Asia-Pacific countries: a survey review. Acta Diabetol 2019;56:815-7.

27 Dias T, Siraj SHM, Aris IM, et al. Comparing different diagnostic guidelines for gestational diabetes mellitus in relation to birthweight in Sri Lankan women. Front Endocrinol 2018;9:682.

28 Bennett S, Radalowicz A, Vella V, et al. A computer simulation of household sampling schemes for health surveys in developing countries. Int J Epidemiol 1994;23:1282-91.

29 Jiang H, Belkin D, Savel'ev SE, et al. A novel true random number generator based on a stochastic diffusive memristor. Nat Commun $2017 ; 8: 882$

30 Zhang J, Tian Y, Wang W, et al. Cohort profile: the Shanghai birth cohort. Int J Epidemiol 2019;48:21-21g.

31 Weinert LS. International association of diabetes and pregnancy study groups recommendations on the diagnosis and classification of hyperglycemia in pregnancy: Comment to the International association of diabetes and pregnancy study groups consensus panel. Diabetes Care 2010;33:e97. author reply e98.

32 LJ L, Tan KH, Aris IM, et al. Gestational retinal microvasculature and the risk of 5 year postpartum abnormal glucose metabolism Diabetologia 2017;60:2368-76.

33 Tran DT, Jorm L, Johnson M, et al. Effects of acculturation on lifestyle and health status among older Vietnam-born Australians. Asia Pac J Public Health 2015;27:NP2259-74.

34 What's for Dinner? An exploration of changes in eating habits and dietary acculturation among new migrants to Australia, 2016. Available: https://wwwamesnetau/-/media/files/research/amesaustralia-migrants-and-food-surveypdf?la=en

35 Hruby A, Manson JE, Qi L, et al. Determinants and consequences of obesity. Am J Public Health 2016;106:1656-62.

36 Luger M, Lafontan M, Bes-Rastrollo M, et al. Sugar-Sweetened beverages and weight gain in children and adults: a systematic review from 2013 to 2015 and a comparison with previous studies. Obes Facts 2017;10:674-93.

37 Duan Y, Zeng L, Zheng C, et al. Inflammatory links between high fat diets and diseases. Front Immunol 2018:9:2649.

38 Aeberli I, Gerber PA, Hochuli M, et al. Low to moderate sugarsweetened beverage consumption impairs glucose and lipid metabolism and promotes inflammation in healthy young men: a randomized controlled trial. Am J Clin Nutr 2011;94:479-85.

39 Koebnick C, Black MH, Wu J, et al. A diet high in sugar-sweetened beverage and low in fruits and vegetables is associated with adiposity and a pro-inflammatory adipokine profile. $\mathrm{Br} \mathrm{J}$ Nutr 2018;120:1230-9.

40 Black MH, Watanabe RM, Trigo E, et al. High-Fat diet is associated with Obesity-Mediated insulin resistance and $\beta$-cell dysfunction in Mexican Americans. J Nutr 2013;143:479-85.

41 Liese AD, Schulz M, Moore CG, et al. Dietary patterns, insulin sensitivity and adiposity in the multi-ethnic insulin resistance atherosclerosis study population. Br J Nutr 2004;92:973-84.

42 Mellin-Olsen T, Wandel M. Changes in food habits among Pakistan immigrant women in Oslo, Norway. Ethn Health 2005;10:311-39. 
43 Kudo Y, Falciglia GA, Couch SC. Evolution of meal patterns and food choices of Japanese-American females born in the United States. Eur J Clin Nutr 2000;54:665-70.

44 Black CN, Bot M, Scheffer PG, et al. Is depression associated with increased oxidative stress? A systematic review and meta-analysis. Psychoneuroendocrinology 2015;51:164-75.

45 Vaccarino V, Badimon L, Bremner JD, et al. Depression and coronary heart disease: 2018 ESC position paper of the Working group of coronary pathophysiology and microcirculation developed under the auspices of the ESC Committee for practice guidelines. Eur Heart $\mathrm{J}$. [Epub ahead of print: 28 Jan 2019].

46 van der Kooij MA, Jene T, Treccani G, et al. Chronic social stress-induced hyperglycemia in mice couples individual stress susceptibility to impaired spatial memory. Proc Natl Acad Sci U S A 2018;115:E10187-96.

47 Plows J, Stanley J, Baker P, et al. The pathophysiology of gestational diabetes mellitus. Int J Mol Sci 2018;19:3342.
48 Benhalima K, Van Crombrugge P, Moyson C, et al. Characteristics and pregnancy outcomes across gestational diabetes mellitus subtypes based on insulin resistance. Diabetologia 2019;62:2118-28.

49 Czech MP. Insulin action and resistance in obesity and type 2 diabetes. Nat Med 2017;23:804-14

50 Guilherme A, Henriques F, Bedard AH, et al. Molecular pathways linking adipose innervation to insulin action in obesity and diabetes mellitus. Nat Rev Endocrinol 2019;15:207-25.

51 Lappas M, Hiden U, Desoye G, et al. The role of oxidative stress in the pathophysiology of gestational diabetes mellitus. Antioxid Redox Signal 2011;15:3061-100.

52 Law KP, Zhang $\mathrm{H}$. The pathogenesis and pathophysiology of gestational diabetes mellitus: deductions from a three-part longitudinal metabolomics study in China. Clinica Chimica Acta 2017;468:60-70.

53 Chen YC. Chinese values, health and nursing. J Adv Nurs 2001;36:270-3 